\title{
Complex Cervical Spine Surgery at the Hospital for Special Surgery
}

\section{Editorial}

\author{
Darren R. Lebl, MD
}

Received: 27 October 2014/Accepted: 14 November 2014/Published online: 6 February 2015

(C) Hospital for Special Surgery 2015

The inaugural complex cervical spine symposium at the Hospital for Special Surgery brought together preeminent thought leaders and innovators in cervical spinal surgery in May of 2013 from around the USA, Europe, and Asia. Topics included advanced cervical spine operative techniques, cervical spine reconstruction, the operative treatment of pediatric cervical spine disorders, deformity, and tumor treatment at the occipitocervical junction. The Keynote Lecture was delivered by Kuniyoshi Abumi, MD, PhD, from Sapporo, Japan, on cervical spine osteotomies and the treatment and reduction of occiptiocervical deformities. Dr. Abumi served as the first president of the Cervical Spine Research Society's Asia Pacific Division and is widely regarded for developing the technique of subaxial cervical spine pedicle screw instrumentation.

Pediatric cervical spine lectures were given by John Dorman's MD from the Children's Hospital of Pennsylvania and Daniel Hedequist, MD, from Boston Children's Hospital. Christoph Seipe, MD, PhD from the Schon Klinik in Munich, Germany, and Roger Hartl, MD, presented their experiences with advanced computer navigation techniques for complex degenerative cervical spine disorders and minimally invasive surgical techniques, respectively. Todd Albert, MD, who has since joined the HSS family as Surgeon-in-Chief, presented techniques for reconstruction of the post-surgical spine, and Edward D. Simmons, MD, presented the experience that he and his father accumulated over several decades with the cervical spine osteotomy that bears his family name, the "Simmon's osteotomy."

Several controversial topics pertinent to modern cervical surgery were debated by leading experts in their respective fields, ranging from motion preservation surgery using disk replacement devices, the treatment of athletes with critical cervical spinal stenosis, and the optimal surgical approach for cervical spondylotic myelopathy using modern techniques. It was my great privilege both to serve as the director of the HSS Complex Cervical Spine Symposium and as guest editor of the HSS Journal's cervical spine special issue. This focus issue of the symposium summarizes many of the cutting edge talks, debate sessions, and expert techniques given by surgeons at the symposium.

\section{Disclosures}

Conflict of Interest: Darren R. Lebl, MD received consultancy fees from Medtronic, Inc., outside of the work.

Human/Animal Rights: This article does not contain any studies with human or animal subjects performed by the any of the authors.

\section{Informed Consent: N/A}

Required Author Forms Disclosure forms provided by the authors are available with the online version of this article. 